\title{
La clínica psicoanalítica a través del cine. El sufrimiento en el registro de lo singular (violencia, psicoanálisis, cine)
}

\author{
Jean Jacques Moscovitz
}

Psicoanalista

Recibido: 19 noviembre 2017; aceptado: 1 de marzo 2018

\begin{abstract}
Resumen
El texto propone considerar la afinidad del cine y el psicoanálisis. A través del análisis de películas como El cielo esperará o Salafistas, el autor interpreta que la captación activa de adolescentes por movimientos como ISIS, los devolvería a lo amorfo inicial, la no-vida, el vínculo con la realidad estaría borrado. ISIS sometería a estos jóvenes a un apoderamiento mortal, revelando la pulsión de apoderamiento con un fin activo (el de matar) y un fin pasivo (el de matarse) fusionando los lugares de verdugo y de víctima.
\end{abstract}

ISIS anuncia la crueldad a modo hollywoodense a partir de imágenes que reflejan una especie de afirmacionismo, con torturas que llevan a la juventud a la muerte.

El autor reflexiona también sobre sublimación de la violencia y sus consecuencias en el discurso y la práctica del psicoanálisis.

Palabras Clave: violencia | crueldad | ISIS | afirmacionismo | sublimación

The psychoanalytic clinic through cinema

the suffering in the register of the singular (violence, psychoanalysis, cinema)

\begin{abstract}
The text proposes to consider the affinity of cinema and psychoanalysis. Through the analysis of films like Heaven will wait or Salafistes, the author interprets that the active uptake of adolescents by movements like ISIS, would return them to the initial amorphous, the non-life, the link with reality would be erased. ISIS would subject these young people to a deadly seizure, revealing the impulse of seizure with an active purpose (that of killing) and a passive end (that of killing oneself) merging the places of executioner and victim.
\end{abstract}

ISIS announces the cruelty in Hollywood mode from images that reflect a kind of affirmation, with tortures that lead youth to death.

The author also reflects on the sublimation of violence and its consequences in the discourse and practice of psychoanalysis.

Key Words: violence | cruelty | ISIS | affirmationism | sublimation

Es algo instalado, haciéndose eco del coloquio $\mathrm{Me}$ morias y luchas, que cine y psicoanálisis deben considerarse de ahora en adelante como disciplinas afines.

Le regard qui bat... es una actividad regular de la asociación Psychanalyse Actuelle en la que se proyectan películas seguidas de debates, que pone en elaboración una clínica psicoanalítica entre sujeto y colectivo, entre íntimo y extremo.

\section{Preámbulo}

El cine que encanta nuestras vidas es el que nunca cede frente a las violencias que hay que combatir; aprende a pasarnos imágenes capciosas, lúgubres, así como el psicoanálisis enseña que hay palabras y afectos silenciados en nosotros, a la espera de volverse conscientes tanto como sea posible, y de liberarnos de ellos. Así, estas dos

jjmoscovitz@gmail.com 
disciplinas nos dan otras palabras, otras imágenes, otras emociones que nos tranquilizan.

Y esto es así a pesar de la violencia que hay en nuestro mundo, donde el artista nos sitúa en el lugar de lector, espectador, analizante, ciudadano, y participa sin cesar en nuestra formación de profesionales del psicoanálisis.

Esto nos da emoción, control, asombro, allí donde nuestra escucha analítica y nuestra cámara interna despiertan al niño que está en nosotros y lo abre al significante.

\section{El Cielo Esperará [Le Ciel Attendra], de Marie-Castille Mention-Schaar (2016)}

Partamos de un ejemplo de ficción, a pesar de las críticas sobre la película en sí misma.

Sinopsis del informe de prensa: "Sonia, de 17 años, estuvo a punto de cometer lo irreparable para 'garantizar' a su familia un lugar en el paraíso.

Mélanie, de 16 años, vive con su madre. Le gusta ir a la escuela, estar con sus compañeras, toca el violoncelo y quiere cambiar el mundo.

Se enamora de un yihadista por Skype.

Podrían llamarse Anaïs, Manon, Leila o Clara y, como ellas, ser reclutadas... ¿Podrán regresar de ahí?”.

Aquí, el cine de ficción se presenta como bello frente a la fealdad extrema de los actos de matanza.

El conflicto entre documental y ficción se reaviva: se trata, respectivamente, del conflicto entre lo colectivo en el nivel político, estratégico, y lo íntimo de cada una y cada uno en el nivel de sus emociones y su angustia.

Durante el debate, se abordó el lugar de lo político, que es clave para entender lo que sucede en el nivel íntimo, dejando al espectador la elección de percibir la dimensión de la violencia social que se despliega en las secuencias sin diálogo, donde solo la imagen del cine da ritmo a la situación, allí donde los protagonistas se encuentran embarcados en nuestra común actualidad.

\section{Salafistas [Salafistes], de François Margolin (2016)}

¿Este documental sería preferible? En enero de 2016, en presencia de François Margolin, se proyecta Salafistas en Le regard qui bat... La película nos muestra la violencia sanguinaria de la guerra de ISIS y pone al espectador en posición de ser responsable frente a lo que debe saber, como consecuencia de un exceso espantoso de imágenes de asesinatos que se ven al final de la película y que las secuencias que preceden van preparando.

Salafistas muestra que ISIS busca generar el susto que obtiene. El cine de ISIS, como sostiene J.-L. Comolli en Daech, le cinéma et la mort, ${ }^{2}$ obedece a las "técnicas fílmicas tomadas del deshonroso Occidente, lo que demuestra, también en eso, la dependencia a ese Occidente. La diferencia radica en que el cine occidental, que muestra la muerte sin cesar, no mata a los actores.

El espectador de una ficción sabe que está viendo ficción, incluso cuando se estremece. Podemos decir que se permite el estremecimiento porque sabe, justamente, que se trata de una ficción". ${ }^{3}$

El hecho de mostrar todo en el cine es enemigo del género humano. Jean-Louis Comolli presenta un "cuadro desesperado de la situación de las imágenes, llevado al extremo por ISIS. Y teme la muerte del cine en su función liberadora...”.

El cielo esperará, como ficción, emplea formas que reclaman al espectador de otro modo. Los rostros de estas bellas jóvenes adolescentes filmados de cerca nos lanzan el desafío de saber en qué momento, de qué modo, surge lo extremo de la violencia asesina y suicida.

Para cada una, cada uno, es el nivel inconsciente, individual, íntimo, el que nos lleva aquí a percibir, ante lo real de esta guerra, que se trata también de una guerra de imágenes. Allí, donde reina el espanto.

\section{La crueldad}

Esta guerra es una captación a través de la crueldad que surge no con el objetivo de tomar el poder, sino para ejercer la crueldad como tal.

Clínicamente, es ir hacia la violencia primordial, la que está antes del trauma individual que da cuerpo a la interioridad psíquica. Es como un retorno a la no-vida, en la que el infante no es ni femenino ni masculino, ni ser animado ni cosa, ni siquiera vivo o muerto.

Balbuceo una hipótesis sobre la captación activa de adolescentes, captación inherente a los crímenes del Estado Islámico contra el humano. La hipótesis es que la captación de estas jóvenes las devolvería a lo amorfo inicial, cuando vida y muerte se acercan al punto de que el nacimiento está en riesgo de volver a la no-vida. Y esto es radicalmente ignorado por estas jóvenes en vida. Es imposible saberlo. Por eso es mucho más activo. 


\section{Lo amorfo}

Lo amorfo que tratamos aquí, ¿aparecería un poco en su conciencia bajo la forma de una sensación de asesinato inminente?

Esto está relacionado con lo que Freud afirma con respecto a lo inanimado, que reina desde siempre en el universo, de tal modo que, en cuanto lo animado surge, lo inanimado continúa su camino en el seno de lo animado, al que intenta volver a atraer hacia él. Es el inicio, para Freud, de la imbricación entre Tánatos y Eros. ${ }^{4}$ Según mi hipótesis, es allí donde se ejerce la captación de muerte.

Volvamos a la película. El desmayo de Sonia, ¿mostraría esto? Su desmayo en la pasarela de la aduana, cuando está por partir a Estambul y Siria, la hace volver al mundo en que su madre está de nuevo presente, aun cuando ella la había aislado, excluido de su realidad. En ese momento, Sonia explica que el vínculo con la realidad se le había borrado, describe su ida a un no-mundo, el de ISIS, que la habría sometido a un apoderamiento mortal si el aferramiento a su mundo arcaico maternal, matricial, por más mínimo que sea, no hubiera tenido nuevamente lugar.

En efecto, aquí está en acto la pulsión de apoderamiento/aferramiento. Toda pulsión se define por su fin, y ese fin es activo y pasivo. Por ejemplo: comer/ser comido, mirar/ser mirado. En este caso, la pulsión de apoderamiento está del lado del crimen y los criminales; el aferramiento, del lado de la vida y las víctimas.

Todo se distribuye según un fin activo, el de asesinar, y un fin pasivo, el de ser asesinado. Aquí, el lugar del verdugo y el de la víctima se confunden. En los atentados, las víctimas se vuelven criminales. El lugar del verdugo y el de la víctima se fusionan, mezclándose en la masacre kamikaze. Lo amorfo mezcla incesto y asesinato de los cuerpos explotados donde los asesinos y asesinados se confunden.

En estos crímenes, que nos muestran a los asesinos desbordando de su goce destructivo, por la puesta en acto de su motricidad, de su motricización suicida, la energía actúa en el nivel motor. Salafistas muestra el cuerpo de los jefes fusionado con la kalachnikov, como los jueces que la ponen por encima de sus códigos de derecho.

Recordemos aquí lo que Freud nombra "tercer inconsciente", como vestigio de la continuación: una especie de inconsciente recibe excitaciones que se envían enseguida a la realidad, sin filtro de un Yo ni de un $\mathrm{Su}_{-}$ peryó, bajo una forma motora inmediata, en plena violencia sin control.
Mi hipótesis también evocaría algún apoyo en Dolto, cuyo ingenio nos falta aquí. Un bebé que está todavía en el útero mata el vientre que lo envuelve y muere allí violentamente, con los sobresaltos de su motricidad premortem. De allí brota nuestro espanto, de una desaparición en un mundo maternal inmensamente asesino ya que está totalmente negado. Negado: la ausencia de evocación de la matriz maternal en los relatos que nos llegan de ISIS nos permiten esta especulación freudiana.

\section{Re-bobinado}

Para usar un término de cine, se trataría de un rebobinado del trauma individual que, normalmente, $\mathrm{da}$ cuerpo a la interioridad psíquica y que, aquí, volvería a la violencia originaria entre muerte, vida, no-vida.

Tanto en la película como durante el debate, el acento puesto sobre las madres indica esta desvinculación del lazo materno. Como una forclusión de una desvinculación que habría que localizar si esas adolescentes que van hacia la muerte volvieran de Siria.

Una frase de los padres se repite sin cesar: "No nos imaginábamos nada de esto, no hubo nada que nos llamara la atención"; el engaño consciente despierta un pasado infantil precoz sobre el cual apoyarse frente al desamparo. La madre primordial y la fase bebé están borrados. La situación que crea este yihadismo asesino llevaría al sujeto adolescente de vuelta a la fase bebé. A merced del apocalipsis. El entorno solo puede recibirlo en un desamparo sin salida, Hilflosigkeit.

El dolor de los padres de niños muertos en Siria es inmenso, es doble, porque jamás verán sus cuerpos ni serán apoyados por las autoridades francesas, que solo ven en sus hijos a enemigos de Francia.

\section{Desamparo sin salida}

Las adolescentes son seducidas, captadas, capturadas y luego "casadas" por Skype. Cuando llegan a Siria, no ven a su "futuro esposo" ya que, probablemente, está muerto o fuera de Siria. Al llegar, reciben como regalo de bodas un gato y... juna kalarchnikov! El gato como símbolo del león y de su fuerza y la AK-47 para asesinar y ser asesinadas.

Evidentemente, la educación parental y especializada, tantas veces invocada, debería sostenernos en nuestro esfuerzo por salvar a esas adolescentes y jóvenes adultas. 
Pero el nivel íntimo, aunque necesario, es insuficiente. Tales retos educativos serán mucho más eficaces, sin duda, por medio de una acción política, colectiva, jurídica. Debe tener lugar un gran juicio como el de Núremberg, que enseñó al mundo los horrores nazis. Cuando la guerra contra ISIS se termine, exijamos que se haga un gran juicio bajo el amparo de un Tribunal Militar Internacional, donde los asesinos expongan sus daños y las víctimas describan sus dolores. Aprenderemos así a hablar de estos crímenes y dejarán de ofrecer a la juventud una falsa utopía tan desastrosa.

\section{Violencias e imágenes}

Concluyamos con algunos comentarios con respecto a violencias e imágenes, evocando esas "Memorias en lucha” del argumento de nuestro coloquio.

Violencias de las imágenes e imágenes de las violencias. O bien es la violencia de las imágenes de goces y pulsiones asesinas, y se trata de la barbarie, o bien son imágenes de las violencias que enmarcan esos goces, transmitidas a través del arte y el cine, y se trata de la civilización.

Recordemos las palabras de Freud, que afirman que el hombre, frente a su incompletud narcisista, enraizada en esa sustancia amorfa originaria, tiene dos formas de actuar: o bien la barbarie, es decir, armas y matanza, o bien la civilización, es decir, la palabra y el derecho. Y dirá que, en Alemania, con el nazismo, ambas se unieron de una forma desconocida hasta entonces.

Esto significa que, con la barbarie, cuando el poder ya se ha tomado, solo se puede ejercer la crueldad, que no es solo un modo de dominar, sino también un ejercicio que prevalece sobre el poder mismo.

Frente a eso, afirmamos que la metáfora de nuestra época sigue siendo, desde fines del siglo XIX hasta hoy, la de la invocación de la palabra y las imágenes sin tener ya la garantía de lo "religioso" para que enmarque, para enmarcar, sí, nuestros deseos y goces. Libres, somos actores y testigos desde entonces de nacimientos conjuntos (o cambios decisivos) del cine, la fotografía, el arte, la literatura. Y del feminismo, el psicoanálisis, el sionismo, el comunismo, la democracia... Todos ellos fueron seguidos inmediatamente por su rechazo, con el surgimiento de totalitarismos devastadores, despobladores de la humanidad, en los que la crueldad está en el lugar del amo.

\section{Jean Améry}

Citamos a Jean Améry, Más allá del crimen y del castigo, ensayo para superar lo insuperable: "Fui llevado a hablar de ello, porque por encima de toda experiencia personal, estoy convencido de que para el Tercer Reich la tortura no era un accidente: ella era su esencia misma”. El espanto a nivel individual es el Hilflosigkeit, en la sin salida de la parte de un Otro, que aquí es radicalmente asesino. Améry se piensa a sí mismo en la tortura como el recién nacido sometido a la ausencia total de la madre. Esta crueldad a nivel singular es lo más originario, lo más inherente a esta substancia amorfa, al fuera del mundo, al inmundo originario que, tomado en masa, actúa en el nivel colectivo. Es allí donde se operaría la captación asesina de jóvenes cuyo Yo dañado lleva a la fabricación de kamikazes. La muerte se vuelve objeto y es utilizada como arma para asesinar/ser asesinado...

\section{$\mathrm{Ni}$ el cielo ni la tierra}

Citamos Ni el cielo ni la tierra, largometraje de ficción de Clément Cogitore (2014), porque muestra ese retorno al extremo originario: en Afganistán, miembros del ejército francés, y soldados talibanes, desaparecen sin dejar ninguna huella. Es un acto de un dios que re-bobinaría todo lo que dio: vida, muerte, cabra, mujer, niño, hombre... Es un retorno al no-mundo hacia el apocalipsis, por medio de asesinatos en miras al fin del mundo. De su descomposición.

\section{Afirmacionismo}

A nivel colectivo, la crueldad es un fin que el nazismo e ISIS persiguen a través de la crueldad del Estado. El nazismo, al negar su acto -mayor en goce asesino cuanto más innombrable se vuelve- es el negacionismo. E ISIS anuncia esta crueldad colectiva por los medios actuales de producción hollywoodense, imágenes para practicar una especie de afirmacionismo, torturas que llevan a la muerte a una juventud a merced de un horror construido...

Así, en Salafistas, se filma este afirmacionismo de las torturas que llevan a los jóvenes a la muerte. La muerte y el crimen se convierten en parte de los ideales de la persona. De este modo, en la última parte de la película, se insertan documentos de espanto para la propaganda 
del Estado Islámico, cuyo modo fílmico es muy rápido. Se despliega de este modo esta crueldad como único objetivo en la destrucción entendida como castigo. Un hombre homosexual -por ser homosexual- es lanzado desde lo alto de un edificio. La cámara nos muestra primero la escena desde la calle, ubicando al espectador en el lugar de testigo y, luego, en el plano siguiente, como participante en el acto de empujar a este hombre atado, encapuchado, hacia el vacío... El espectador se convierte así en cómplice de los asesinos.

Las películas Shoah de Lanzmann y Belzec de Guillaume Moscovitz, entre otras, muestran de qué modo es la responsabilidad del espectador, a quien se debe reclamar frente a tales imágenes, que son muy necesarias para volver a centrar la violencia en vistas de su sublimación.

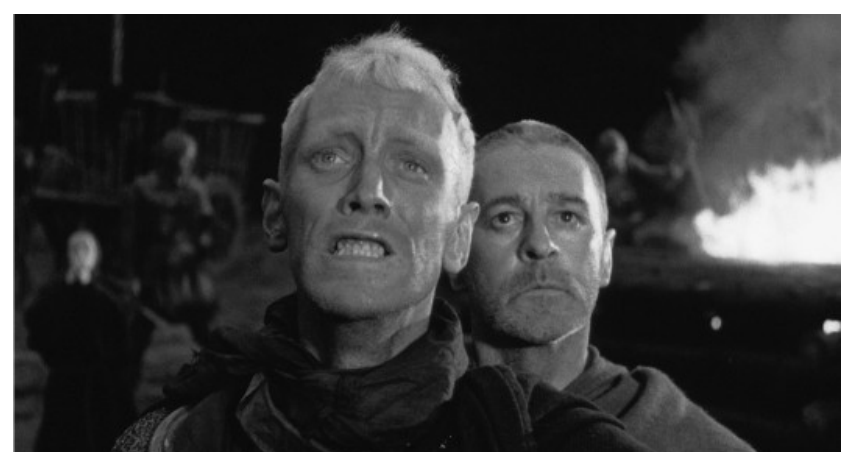

\section{Sublimación}

Por "sublimación de la violencia" entendemos, como dice Freud, que se vuelva Geistigkeit, progreso de la vida de la mente, descubrimiento en sí de su deseo de asesinato al padre primordial y, a partir de ello, el surgimiento de la renuncia a las pulsiones. Eso nos dejaría impotentes si las artes (todas las artes y las disciplinas de la palabra) no existiesen. Ellas, que son la clave de la sublimación de nuestras propias pulsiones. Especialmente el arte de las imágenes del cine, ese gran sueño que nos enseña a despertarnos para luchar.

La violencia es en adelante un concepto psicoanalítico que precede el trauma y su trayecto estructurante para el sujeto.

¿Modifica la práctica del psicoanálisis y llama a precisar sus límites, incluso la (in)eficacia? ¿Cómo? ¿La violencia se transforma en discurso, liberando nuestro Yo o, al contrario, se queda en estancamientos de goces aún activos que, al quedar subterráneos, no develados, tienen consecuencias ocultas propias a las desapariciones colectivas del siglo XX y sus ataques graves a la civilización? Una violencia tal "silenciada" tiene consecuencias en el psicoanálisis, en su discurso, y en su práctica. El cine es, en este sentido, un apoyo para nosotros. ¿Lo somos también nosotros para él?

Traducción: Salomé Landivar

1 Fue proyectada en Le regard qui bat... en noviembre de 2016. El presente comentario forma parte de la obra colectiva coordinada por J.-J. Moscovitz, editorial Érès, noviembre de 2017. Algunos fragmentos fueron también expuestos en Barcelona el 26 de marzo de 2017, con el título Destructivité entre sujet et collectif [Destructividad entre sujeto y colectivo].

2 Comolli, J.-L., Daech, le cinéma et la mort, París, Verdier, 2016.

3 Traducción propia a partir de la cita del autor [N. de la T].

4 Freud, S., Malaise dans la civilisation, París, PUF, 1971, p. 41 [trad. esp., desde donde se tomó la traducción de aquí abajo: «El malestar en la cultura», en Obras completas, traducción de J. L. Etcheverry, Vol. XXI, Buenos Aires, Amorrortu, 1986, p. 114-115]. «Partiendo de especulaciones acerca del comienzo de la vida, y de paralelos biológicos, extraje la conclusión de que además de la pulsión a conservar la substancia viva y reunirla en unidades cada vez mayores, debía de haber otra pulsión, opuesta a ella, que pugnara por disolver esas unidades y reconducirlas al estado inorgánico inicial. Vale decir: junto a Eros, una pulsión de muerte; y la acción eficaz conjugada y contrapuesta de ambas permitía explicar los fenómenos de la vida». 